\title{
Translating multimodal texts in space: A case study of St Mungo Museum of Religious Life and Art
}

\author{
Min-Hsiu Liao \\ Heriot-Watt University, United Kingdom \\ M.Liao@hw.ac.uk
}

\begin{abstract}
Multimodality has received considerable critical attention in Translation Studies over the past decades. However, how translations interact with or within three-dimensional material space is still under-researched. This article proposes to use the study of geosemiotics (Scollon \& Scollon, 2003) as the theoretical framework within which to explore this new territory. The case study was carried out at the St Mungo Museum of Religious Life and Art in Glasgow. The multimodal analysis divides museum space into four ranks: the museum surroundings, the museum building, the museum exhibition and the museum objects. The findings reveal that the translated exhibition texts interact with the four ranks of spaces to consistently minimize the narratives of Christian heritage in Glasgow and manifest a multi-religious and multi-ethnic Scottish identity. This study demonstrates how the (non-)provision of translations has the potential to influence the construction of in-place meaning in the multimodal museum space.
\end{abstract}

\section{Introduction}

Multimodality can be defined as "the use of several semiotic modes in the design of a semiotic product or event" (Kress \& Van Leeuwen, 2001, p. 20). In Translation Studies, the concept of multimodal texts seems to have been associated mostly with audiovisual or multimedia texts, that is "the processing and presentation of information in two or more media simultaneously" (Cattrysse, 2001, p. 1). Typical examples of multimedia text include films and television programmes. A significant number of studies have been devoted to these types of text, and many of them address the problems of technical constraints on the translation of verbal texts imposed by other modes such as images and soundtrack (see Gambier \& Gottlieb, 2001; Orero, 2004). Other multimodal texts have also gradually begun to receive some attention from translation scholars. Some examples are opera (Mateo, 2007), picture books (Oittinen, 2001), comics (Zanettin, 2008) and video games (O’Hagan \& Mangiron, 2013).

These studies on multimodal translation have challenged Translation Studies in a number of ways (see Gambier \& Gottlieb, 2001; O’Sullivan, 2013). However, compared to the wider issues that have been explored in multimodal discourse or visual analysis, it seems that so far the focus on multimodality within Translation Studies is still limited. To date, little is known about how translations interact with or within three-dimensional material space. This study attempts to explore this new territory by examining written translations in a museum site, as museums have often been chosen for collecting data for exploring three-dimensional space (e.g., Pang, 2004; Ravelli \& McMurtrie, 2015).

Museum translation is a relatively under-researched area in both Museum Studies and Translation Studies (see Liao, 2018). Of the limited number of existing studies, only a few have begun to explore museum communication as a multi-semiotic event (e.g., Jiménez Hurtado \& Soler Gallego, 2015; Neather, 2008, 2012; Sell, 2015). Physical features in museum space, such as architecture, floor plans and circulation paths, remain unaddressed by translation scholars. In this article, a case study is carried out to examine how translation interacts with museum space and museum visitors in the St Mungo Museum of Religious Life and Art in Glasgow ("St Mungo Museum"). 
Specifically, this article aims to answer the following research questions:

- How do verbal texts form part of the museum space?

- How do verbal texts guide visitors to perceive the space, and does this influence their perception of the exhibitions in the museum?

- Following on from the first two questions, are there differences between the source text (ST) and the translated text (TT) regarding the museum space?

\section{Theoretical framework: geosemiotics}

For this research on translated texts, we need to make a link between space and verbal texts. For this purpose, we find the theory of geosemiotics developed by Scollon and Scollon (2003) particularly relevant. Geosemiotics is defined as "the study of the social meaning of the material placement of signs in the world" (Scollon \& Scollon, 2003, p. 110). This theory brings together well-established studies which have previously not been integrated to form a single and coherent framework for the analysis of in-place meaning, such as discourse analysis, social psychology, communication studies and cultural geography. Specifically, four components constitute the system of geosemiotics: social actor, interaction order, visual semiotics and place semiotics.

Social actor is "the habitus of individual beings" (Scollon \& Scollon, 2003, p. 166). Each individual located at a certain place reading a particular text in a certain environment has their history - for example, the languages they speak, the place they come from - and these influence how they interpret the texts on a particular occasion. In the museum settings, different people standing in front of a displayed object reading the same label can create different narratives of the exhibition because of their personal background. It can even be argued that the habitus of these visitors shapes their museum experience before they even visit the museum.

Interaction order is a concept taken from Goffman (1983). It refers to the conventional sets of social relationships, which we may observe or challenge, and this is closely related to how we see self and other in this social relationship (Scollon \& Scollon, 2003, p. 16). Taking the site of St Mungo Museum to illustrate this concept, the curator recalled how some religious believers perceived the museum as a religious rather than a secular place, and contested that religious conventions needed to be followed in the placement of a religious object. Disagreement with the way in which the museum interprets certain religious practices has even led to visitors' damaging the exhibited objects (Carnegie, 2009, p. 163).

Visual semiotics in this framework is based on Kress and Van Leeuwen (1996, 2001), and is broadly defined in this framework as "any and all of the ways in which meaning is structured within our visual fields" (Scollon \& Scollon, 2003, p. 11). A range of tools from Kress and Van Leeuwen $(1996,2001)$ are employed in this study to examine the visual composition, such as modality (colour saturation, colour modulation, brightness, etc.) and composition (centred, polarized, etc.). However, an important extension of visual analysis in this theory is the focus on how visual images are placed in the real world, and how social actors index these images and therefore construct their ongoing social performance. In other words, this theory is interested in "how images mean what they mean because of where we see them" (Scollon \& Scollon, 2003, p. 84).

Finally, place semiotics is a term coined by Scollon and Scollon (2003); it refers to "the huge aggregation of semiotic systems which are not located in the persons of social actors or in the framed artifacts of visual semiotics" (Scollon \& Scollon 2003, p. 8). Examples of place semiotics include architecture, urban planning and landscape analysis. This is the most crucial component of the four, because "the central thesis of geosemiotics is that exactly where on earth an action takes place is an important part of its meaning" (Scollon \& Scollon 2003, p. 18; original emphasis). 
Overall, the framework of geosemiotics can be summarized as follows: the in-place meaning is created through a particular human being, with their discursive background, behaving in a social relationship regarded by them as relevant and appropriate, influenced by any visual semiotics within their visual fields, from the physical place they are situated in. This framework allows us to examine whether the differences between the exhibition texts in the ST and in the TT provided by the St Mungo Museum, belonging to the component of visual semiotics in the system of geosemiotics, may have an impact on pointing the two broadly different groups of social actor-museum visitors relying on the ST and the TT - to construct different in-place meanings.

Despite providing useful insights for the present study, there are some limitations in geosemiotics. First, the theory is mainly illustrated using multimodal texts containing relatively few words, such as shop signs and road signs. As the authors explained, "because so little language is involved ... we can see fairly clearly how the different elements of the indexicality-indexable linkage are working" (Scollon \& Scollon, 2003, p. 14). For example, the authors gave a detailed example of how the two-word traffic sign "ONE WAY" interacts with the visual semiotics of an arrow vector, and the place where it is placed, to create the meaning of "driving only in one direction". This book gives no examples of analysing longer verbal texts or a large number of coherently linked texts, such as labels in museums. In longer texts, it is likely that not all the words are indexical or deictic, ${ }^{1}$ or the texts may index a more complex structure of places. Secondly, as these examples are mostly taken from open and public spaces, in contrast to the purposefully designed spaces such as museums, the theory does not provide a systematic tool for analysing place semiotics. In Scollon and Scollon (2003), the analyses of place semiotics are mainly ad hoc descriptions of contextual background relating specifically to the examples given (e.g., the reading conventions in different Chinese communities). Thirdly, despite recognizing the role of social actors and their individual background in geosemiotics, no methodology is offered to examine this component, apart from some passing comments, for example: "to test these ideas we and our colleagues conducted focus groups and interviews in which participants were asked to discuss a variety of photographs of signs" (Scollon \& Scollon 2003, p. 134). These are the issues that we need to solve in this study, and will be further explained in the section on data collection and methodology.

Finally, one obvious limitation of this theory is that it does not address the role of translated texts in space directly, notwithstanding some comments on public signs in multilingual communities. We argue that the way in which verbal texts guide visitors to perceive the museum space is particularly relevant to a study of translation, because users of translations are often tourists from other countries or members of a minority community in a multilingual society; consequently, they may not be as familiar with the museum and its related culture as the readers of the ST. In a discussion of "exhibiting other cultures", Lidchi (1991, p. 166) argues that it is more difficult for visitors to establish a common ground with objects from distant and unfamiliar cultures, so the accompanying texts play a crucial role in "navigat[ing] the reader on a directed route through potentially complex and unfamiliar terrain". Therefore, visitors who are unfamiliar with the source culture of the museums or the exhibited objects may be more dependent on interpretations provided by museums in a range of forms such as object labels, audio guides and interactive touch screens. ${ }^{2}$ It is therefore of interest to examine whether and, if so, how the STs and the TTs in museums point visitors towards constructing different in-place meanings. 


\section{A case study: St Mungo Museum of Religious Life and Art}

\subsection{Background of the museum}

St Mungo Museum is operated by the Glasgow City Council. The aim of the museum is to "promote mutual understanding and respect among people of all faiths and none", as explicitly stated in the entrance foyer.

O'Neil (2006) and Carnegie (2009) provide a detailed account of their involvement in curating this museum. Both point out that this museum was designed to reflect the multi-ethnic Glasgow identity: "it aims to reflect the much more complex identity of Glasgow and Scotland as a multi-faith rather than a mono-cultural society" (O'Neil 2006, p. 40). From the curators' accounts, it can be observed that both are cautious in defining this space. O'Neil (2006) defines it as "a safe arena which is secular but borders the religious or spiritual domain" (p. 42). Carnegie (2009) explains that "despite being adjacent to Glasgow Cathedral, ... it is a secular space which attempts to make sense of the central role and importance of religion in people's lives" (p. 160). Both curators clearly emphasized the word "secular" and tried to present religion in a more neutral or "museumized" manner.

Despite the aim of promoting an understanding of and respect for the multi-faith community, both curators highlight the fact that this museum is a former cathedral building and located within a Catholic square in Glasgow, and therefore the museum inevitably projects a strong Christian message. The clearest message of Christian tradition comes from the name "St Mungo", Glasgow's patron saint who brought the Christian faith to Scotland. Carnegie (2009, p. 161) admits there were concerns about whether this choice of name might discourage some potential visitors from the local community, but the decision was made by the ruling council at that time. Carnegie (2009) further points out that despite their aim of displaying world religions, this exhibition is interpreted "from a Western perspective, to raise themes of global importance" (p. 168, emphasis added). O'Neil (2006) also makes it clear that the museum "does not pretend to be objective and value-neutral" (p. 41).

These conflicting discourses between a traditional Christian Glasgow identity and a multi-faith Glasgow identity promoted by the museum will form the basis of the following analysis of the museum space.

\subsection{Data collection}

For the purposes of this research, three sets of data have been collected. First, a set of field notes has been compiled based on three field trips to the museum at different stages of the research process in March and August 2017, and again in March 2018. During the three trips, the external and internal spatial features of the museum that have caught the author's attention were noted down and photographed. Leaflets and other useful documents from the museum were also collected.

Secondly, all the multilingual "exhibition texts" 3 in the three permanent gallery exhibitions were photographed. For the convenience of references, in what follows all the exhibition texts will be referred to as "labels". English is the source language in this museum, either presented above or to the left of the TTs. The translated languages are organized from top to bottom in alphabetical order: Arabic, Gaelic, Mandarin Chinese and Urdu (see Figure 1). Overall, 46 multilingual labels were collected. For the analysis of geosemiotics, the manner in which all the translated labels were placed in the museum space were observed. The detailed linguistic analysis will include only the English and the translated Chinese texts, these being the author's specialist languages. 


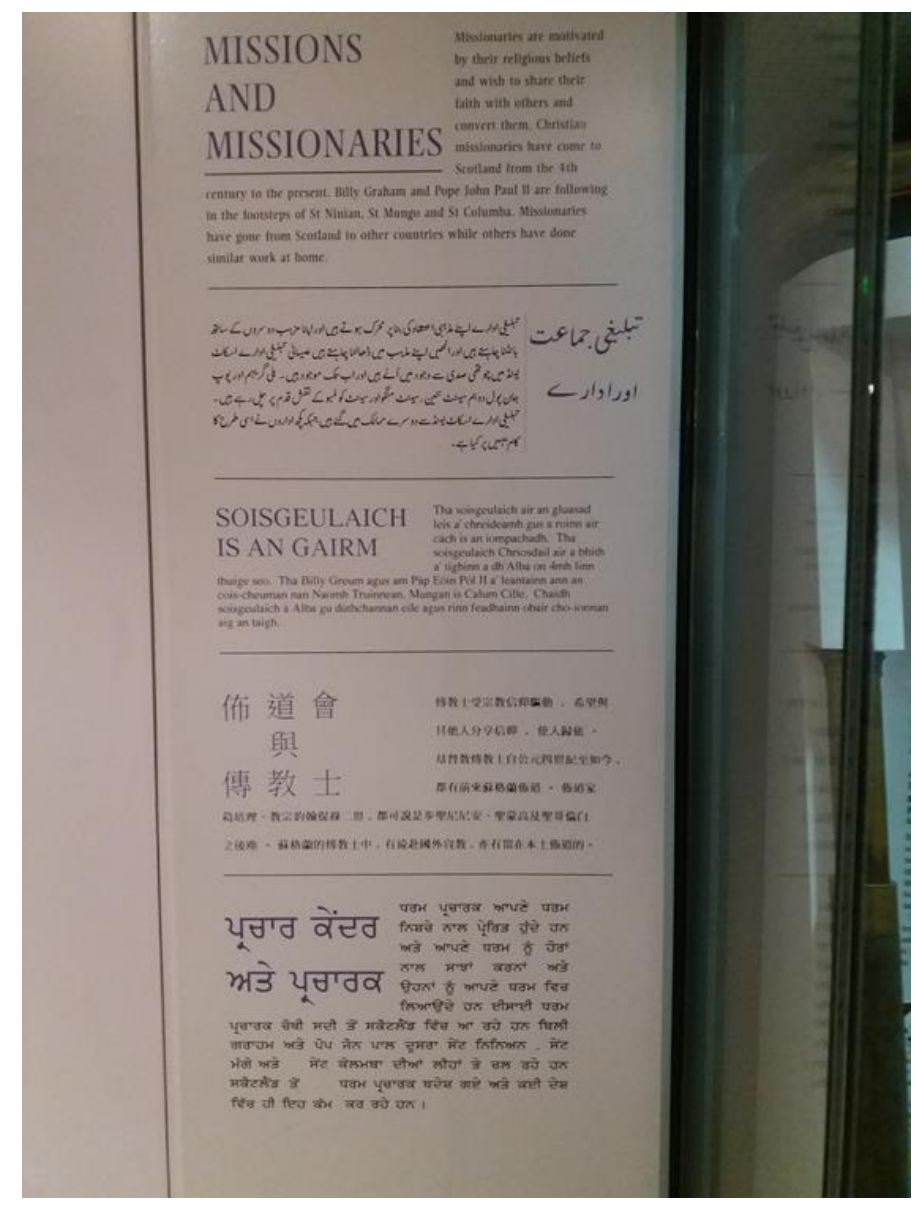

Figure 1. An object label in the museum (photo taken by the author)

Thirdly, in order to better understand the role of social actors, visitors' comments from three online travel reviews were collected, including a total of 266 comments from TripAdvisor; 54 reviews from Google Review; and 5 reviews from a Chinese travel forum Qiongyou, all of them collected on 15 May 2017. Visitors' comments are commonly used as data in audience research in museum studies (MacDonald, 2005) and recently comments on travel review websites such as TripAdvisor have been used in a number of museum studies (e.g., Carter, 2016; Owens, 2012).

It is perhaps useful to clarify here that this study does not intend to measure the effect of verbal or visual signs on visitors, as it is not possible specifically to identify the language profile of the commenters. An in-depth analysis of visitors' comments or an observation of visitors' behaviour is beyond the scope of this study. Visitor comments in this study are intended to be used only as a further set of data to triangulate our findings from the multimodal analysis of in-place meaning.

\subsection{An analytical model of museum space}

Since the theory of geosemiotics did not provide a systematic tool for analysing place semiotics, in order to analyse museum space in a systematic manner, we consulted the studies of museum space (Hiller \& Tzortzi, 2011; Ravelli \& McMurtrie, 2015) and a systemic functional framework for museum exhibitions developed in Pang (2004, pp. 5859). Hiller and Tzortzi (2011, p. 283) point out that space is an intrinsic aspect of human 
activity, not just background; and meaning is constructed not only through properties of but also relationships between spaces. The museum space not only refers to its properties - for example, the style of architecture, the material of the building - but also relationships between spaces - for example, how one gallery leads to another and how visitors move around in the museum. To be more concrete, Pang (2004) divides exhibition space into four categories for analysis: a museum (as a site), a gallery (as an exhibition space), an area (as a particular exhibition room), and an item (as a particular displayed unit).

Pang's categorization is useful, but its emphasis is more on the internal space of a museum rather than on external space. In the case of St Mungo Museum, as observed in the curators' discussions above, the surroundings of this museum play a crucial role in determining how it may be perceived by the visitors. Thus, we decided to divide Pang's category of "museum (as a site)" into the subcategories "museum surroundings" and "museum building". Furthermore, since St Mungo Museum is a relatively small museum with only three galleries, Pang's categories of "gallery" and "area" are combined into one category, "museum exhibition".

After the four categories were decided on, the notes on the spatial features of the museum taken during the field trips were examined and these features were attributed to an appropriate category by the researcher, according to the description of each rank of space, as explained in Table 1.

Table 1: An analytical framework for the museum space

\begin{tabular}{|l|l|}
\hline Spaces & Spatial Features \\
\hline $\begin{array}{l}\text { Museum } \\
\text { surroundings }\end{array}$ & $\begin{array}{l}\text { This rank concerns where a museum is located, what buildings are around it, } \\
\text { and what visitors can see from the museum. }\end{array}$ \\
\hline $\begin{array}{l}\text { Museum } \\
\text { building }\end{array}$ & $\begin{array}{l}\text { This rank concerns the museum building itself, including its external } \\
\text { architectural appeal, the properties of the building, or simply what the building } \\
\text { looks like from the outside. }\end{array}$ \\
\hline $\begin{array}{l}\text { Museum } \\
\text { exhibition }\end{array}$ & $\begin{array}{l}\text { This rank relates to the internal layout of the museum, including the floor plans, } \\
\text { the exhibition rooms, the circulation path, etc. These spatial features affect how } \\
\text { visitors move around in the museum from one location to another. }\end{array}$ \\
\hline $\begin{array}{l}\text { Museum } \\
\text { objects }\end{array}$ & $\begin{array}{l}\text { This rank indicates how objects are displayed in relation to other semiotic } \\
\text { modes, and how they interact with the above three ranks of space. }\end{array}$ \\
\hline
\end{tabular}

\section{An overview of the museum space}

This section begins with an overall analysis of the four ranks of space in St Mungo Museum; in particular, it considers the ways in which the contested religious discourses are embedded in space. Regarding the museum's surroundings, the museum is located in Glasgow's Cathedral Square, and the nearby buildings include Glasgow Cathedral, Glasgow Necropolis and Glasgow Evangelical Church. The museum building was 
established in 1989, having originally been owned by Glasgow Cathedral. It was converted into a museum of religions in 1993. The architecture emulates Scottish baronial style, reflecting the architecture of the Bishop's Castle, a medieval castle in Glasgow.

The internal structure of the museum is divided into three floors and four exhibition galleries. The ground floor contains an information desk, a shop and a cafe. On the first floor, the first gallery is the Gallery of Religious Art (see Figure $2^{4}$ ). It is a bright and open space, with a display of a selection of religious and folklore objects. A smaller room adjacent to this gallery is the Gallery of Religious Life. This room is dimly lit and the exhibition cases are densely structured along a U-shaped pathway (see Figure 3). The room is laid out in such a way that visitors are guided to follow a fixed pathway. The second floor houses a temporary exhibition room. The Scottish Gallery on the third floor is an open, bright space, providing some hands-on activities for young visitors.

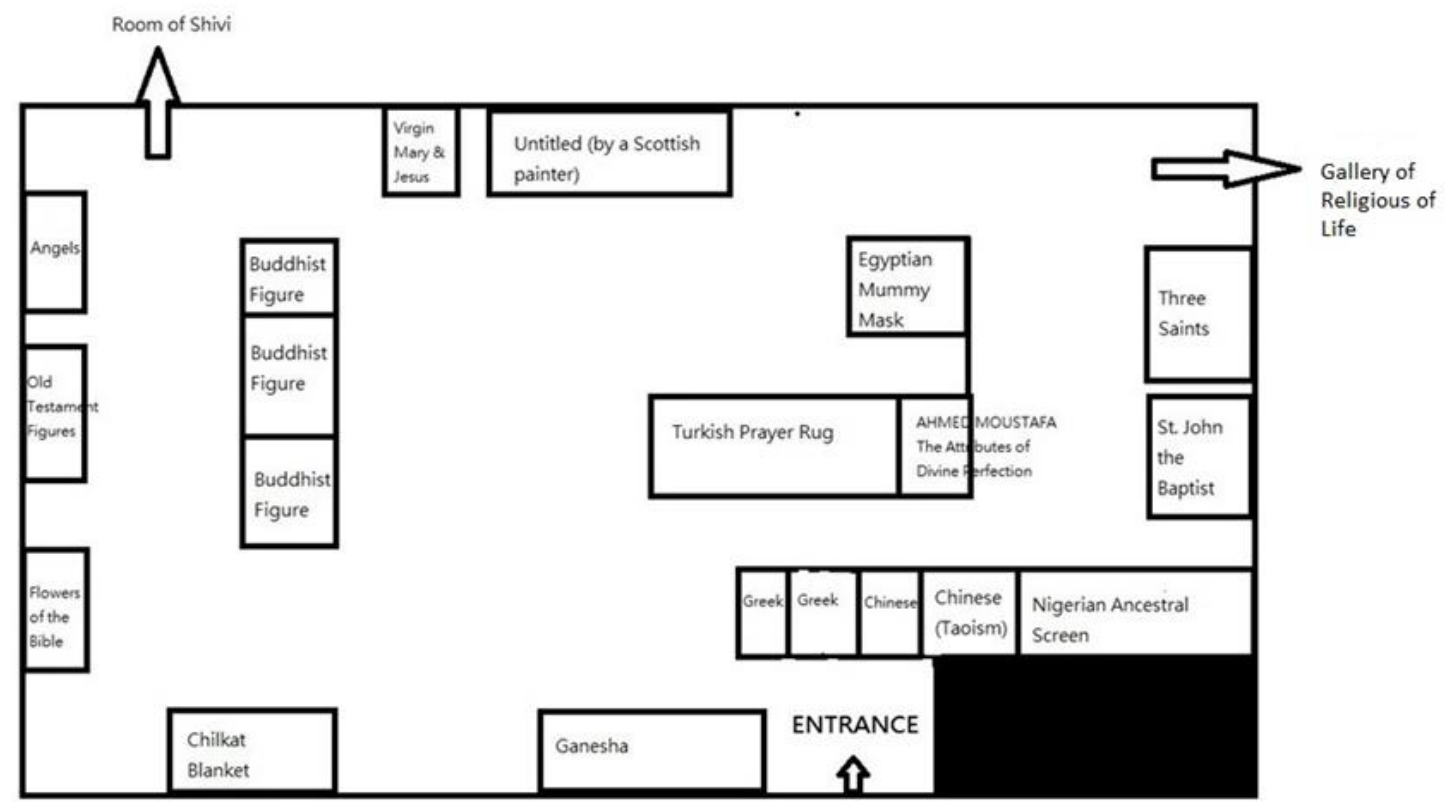

Figure 2. The Gallery of Religious Art 


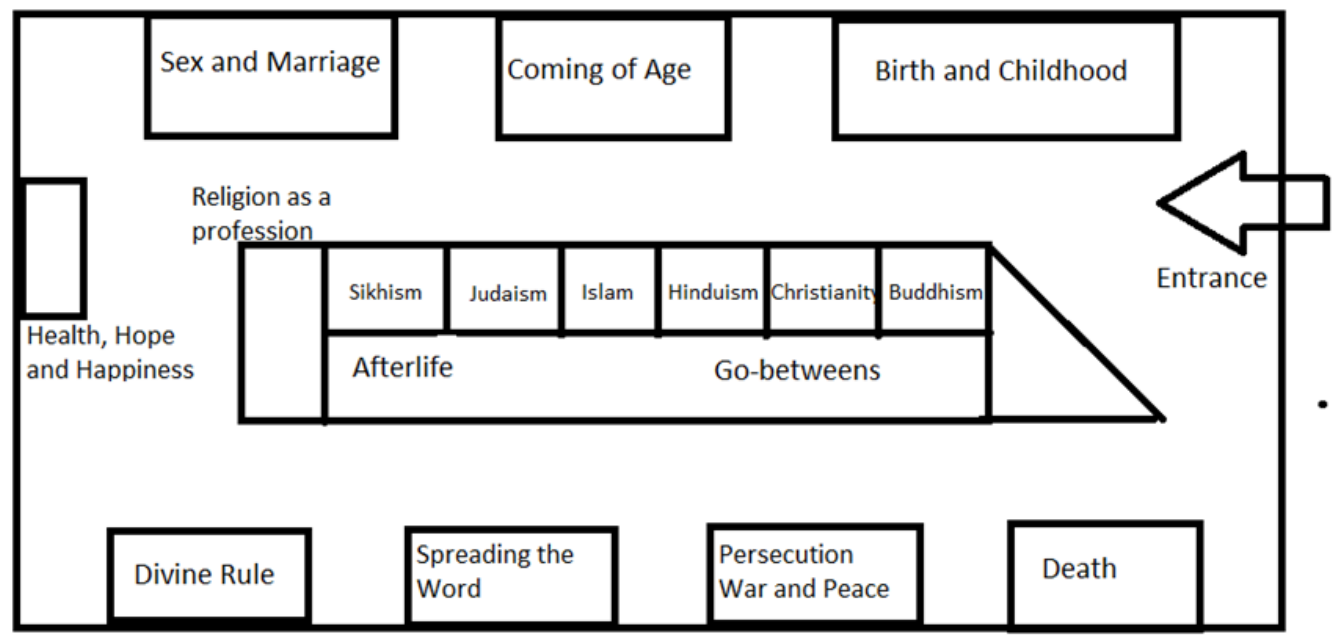

Figure 3. Layout of the Gallery of Religious Life

Regarding the arrangement of displayed objects, in the Scottish Gallery and the Gallery of Religious Life the objects are grouped thematically according to religions. A thematic label usually accompanies an exhibition case. In the Gallery of Religious Art aretfacts are displayed one by one and each has an object label.

The above analysis shows that the museum surroundings and the museum building are clearly characterized by a Christian spatial discourse (e.g., being located in Glasgow's Cathedral Square). Many of these spatial features can be seen by visitors before they enter the museum and they probably prompt visitors to form an expectation of what the museum is about. But the internal design sends a stronger message about the multi-faith values in Glasgow, containing as it does a mixture of religious and folklore objects from around the world. How different religions are conceived and practised by the followers inhabiting Glasgow is explained. The ways in which objects are organized religion by religion and the religions are presented in an alphabetical order seem "neutral" enough and reflect the aim of respecting all religions. Nevertheless, a close examination of the exhibition rooms reveals some interesting spatial features.

In the Gallery of Religious Life (Figure 3), for example, the six religions displayed in the thematic cases in the middle of the room are surrounded by a cycle of life, which, although it can be interpreted as universal, arguably embodies curatorial decisions made by the institution - for example, the concepts of "afterlife" and "go-betweens" are not shared by all religions, and the decision to have an exhibition case on "persecution, war and peace" strongly reflects an institutional ideology rather than a universal or neutral religious discourse.

The layout of the Gallery of Religious Art also supports the view that this is a religious museum from a Western perspective. As can be seen in Figure 2, the gallery is an open space consisting of roughly an outer and an inner circle, with objects of religions from around the world in the "inner circle" (e.g., Buddhist figures, Turkish prayer rug and Egyptian mummy mask) surrounded by those that originated in the city of Glasgow and Christian objects on the three walls.

The internal space of the museum exhibition is also linked to the surroundings: this is perhaps most explicitly evident in the Scottish Gallery, where a window invites visitors 
to view the surroundings and a label explains the six important buildings nearby. Figure 4 shows the view through the window.

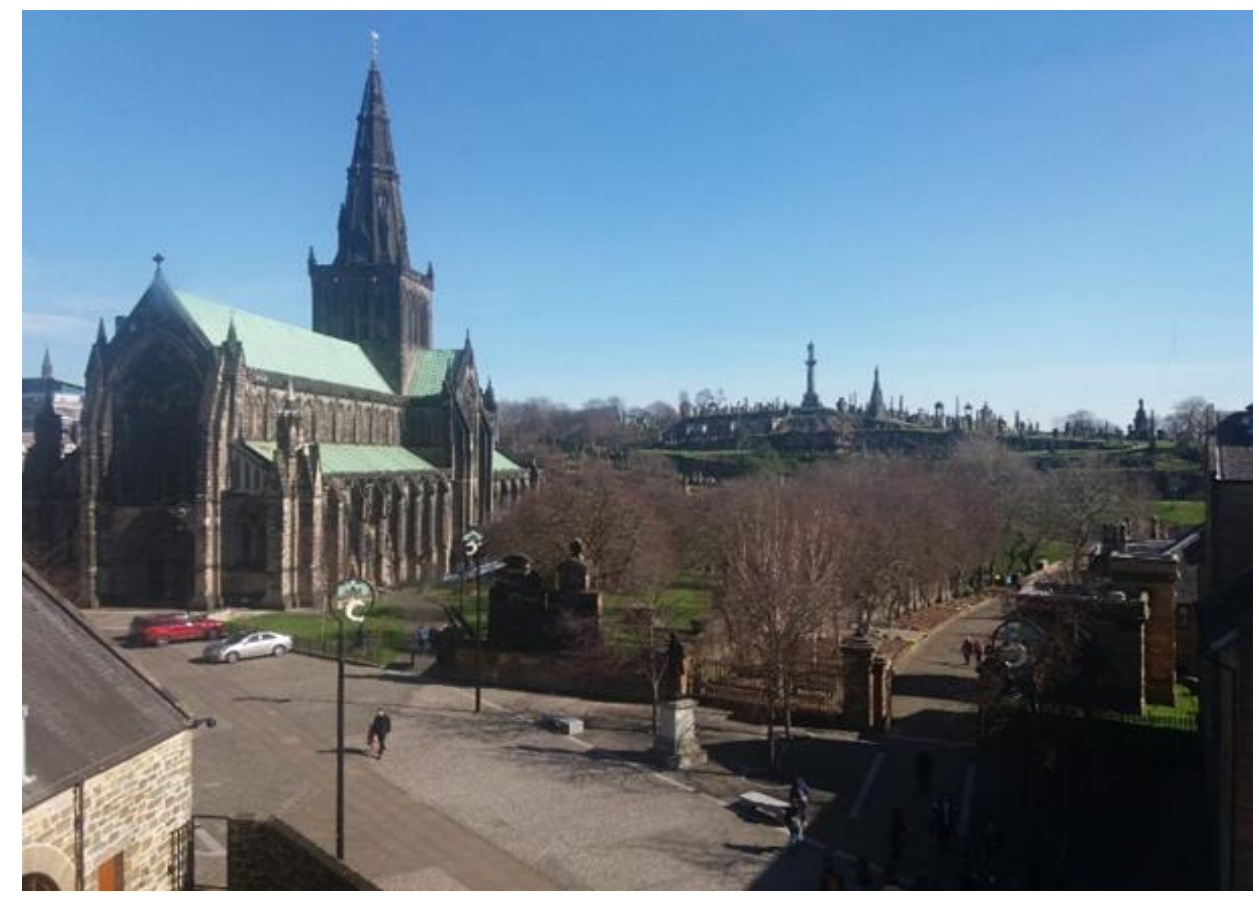

Figure 4. A window view from the museum (photo taken by the author)

Overall, an analysis of the four ranks of museum space seems to reveal that the spaces of the four ranks all contribute to the discourse of both a Christian and a multi-faith Glasgow. In the space, the textual guides also help make some spatial features more explicit: for example, by pointing visitors to the cathedral surroundings.

We now attempt to triangulate this multimodal analysis with some recurrent themes that emerge from the visitors' comments. One of the themes is reference to the surrounding buildings of the museum, particularly the Catholic Cathedral. For example: "[the museum is] situated beside the Cathedral, close to the Necropolis and across the road from the Provand's Lordship." Some comments further indicate that the museum's surroundings is the reason for visiting: "very close to Cathedral and the Necropolis so well worth calling in here if you are visiting."

The reference to architectural style also appeared in visitors' comments. It is interesting to note that several comments refer to the building as the church, and one comment refers to the impact of the architeucture on the museum experience: "being in here is a bit like entering a church you are in awe of the place." One comment further illustrates how the external features of the museum form the expectation of the visit: "the appearance of the building does not feel like dealing with various religions."

In terms of comments on the collection, there are mixed opinions. Many comments contain keywords that reflect the aim of the museum, such as "muliticuture", "world religions", "various religions", "all major religions". On the other hand, a number of comments perceive the collection as mainly Christian-for example: "The collection is mostly but not entirely Christian."

As stated above, it is not possible for us to measure the effect of the place semiotics on visitors' experiences. However, the brief overview of the comments supports some of our observations and arguments based on geosemiotics. First, the spatial features play a clear role in visitors' experience, even before they start their visiting experience. 
Secondly, the conflicting discourses between a Scotland of Christianity and a multicultural religious heritage also appeared in visitors' comments.

The next section investigates further the role of translations in the space of $\mathrm{St}$ Mungo Museum.

\section{The translated spatial text}

An initial observation of the multilingual labels in the museum shows that the STs are not fully translated. The Gallery of Religious Life has wall labels that accompany each exhibition case. All of the labels are translated, though with some shifts at micro-level, such as lexical choices. Some labels also accompany individual objects inside the exhibition cases, but these are available in English only. The Gallery of Religious of Art has object labels that accompany individual artefacts, but to varying degrees the translated labels are shorter than those of the ST. The Scottish Gallery has thematic labels explaining each religion, but only some of them are translated. The manner in which translations interact with the four ranks of museum spaces is examined below.

\subsection{Museum surroundings and buildings}

As discussed above, one prominent spatial feature of the museum surroundings is its position adjacent to Glasgow Cathedral and other buildings with Christian connections, and this is also evident in the visitors' comments. However, how the museum is related to its surroundings, as indicated in the verbal texts and the objects in the museum seems to have shifted in the translated text, because of the selective provision of translations in the galleries.

This selection is particularly clear in the Gallery of Religious Art: the labels of all the objects in the outer circle on the three walls have only the title translated, and all of these objects happen to be related to Christianity and Glasgow's history (see Figure 2). Examples include: "The Bible: Roses", "Old Testament figures", "Angels" and "Friends and followers of Christ". These are all stained-glass panels taken from churches in Glasgow and they illustrate distinctive features of Glasgow. These displayed artefacts interact with the museum architecture to emphasize the religious tradition and heritage in Glasgow. On the other hand, all the objects in the inner circle, including religious and folklore artefacts from China, Australia and Africa, have longer translations - still reduced, but more than just the titles.

Another spatial feature that highlights the museum surroundings, as indicated above, is the window on the top floor of the museum. The label next to the window explaining the surrounding buildings can be considered as an invitation encouraging visitors to link the internal and the external spatial features. However, this label is not translated, and therefore the visitors whose mother tongue is one other than English are not introduced to the Christian buildings in the museum's surroundings.

\subsection{Museum exhibitions}

The selective translations in the Gallery of Religious Art, as discussed above, not only affects visitors' perceptions of the museum's surroundings, but also how the museum texts are able to guide visitors to move around in the exhibition room. The layout of this gallery is relatively open-plan, as demonstrated in Figure 2 above, so we could probably argue that the placement of museum texts encourages visitors to move around in the open space to choose objects that they want to look at more closely or to learn more about. However, the content of the object labels on the three walls of the gallery is not translated. 
We argue that this design of place semiotics by not providing translations of labels may prompt the visitors to a different in-place meaning, that is, they would lead to visitors' skipping the objects in the outer circle or their being less engaged with them. As a result, we may imagine that as regards the physical movement of visitors in this space, those who rely completely on the verbal texts for acquiring knowledge of the objects will either be diverted into a more fixed circulation path (i.e. only the inner circle) or their movement in the outer circle may be speeded up simply because they have less to read and they are not encouraged to look more closely at the objects.

In the result, the visitors could possibly be diverted to world religious objects only, and their contact with Christian objects may accordingly be reduced. This illustrates how the placement of (non-)translations in space can influence which visual semiotics fall within the visual fields of social actors, and can therefore influence their construction of in-place meaning.

\subsection{Museum objects}

Museum labels guide visitors to look more closely at objects, and one effective way to engage visitors is by directing them to look at specific points on an object. Below we will use an object in the Gallery of Religious Art to explain how an object is linked to the other ranks of museum space and the aim of the museum (Figure 5).

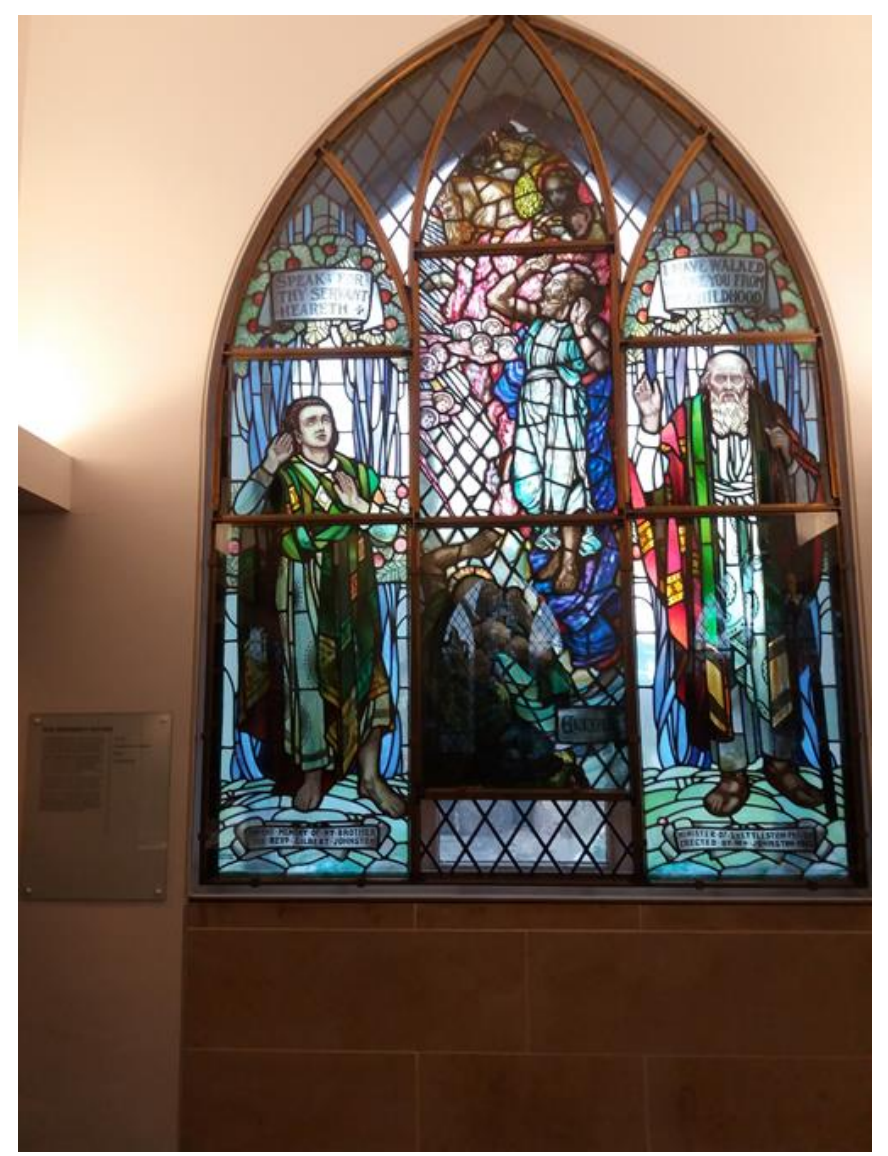

Figure 5. A stained-glass window in the Gallery of Religious Art (photo taken by the author) 
A label is placed at the left-bottom side of this window. The English text comprises 298 words, including the title "OLD TESTAMENT FIGURES"; three subsections explain the three glass panels from left to right:

- $\quad$ The young Samuel;

- $\quad$ Elijah and the Fiery Chariot; and

- Samuel as an old man,

and a concluding paragraph highlights how this stained-glass panel exemplifies a Glasgow technique called "the cameo technique". In terms of the object-text interaction, the English text directs visitors through the space on the displayed unit-from left to right, following the order of the subsections, and pointing visitors to specific areas on the window, for example - "the inscription at the top of the window".

At the museum level, the label highlights the Glasgow heritage and historical context, with phrases such as "the window was made for Old Partick Parish Church in Glasgow by William Meikle \& Sons in 1905". These references point visitors to the wider space the museum inhabits, that is, Glasgow city.

The languages are arranged in two columns: a long English text on the left and the four translations of only the object title on the right, listed from top to bottom in alphabetical order: Arabic, Gaelic, Mandarin Chinese and Urdu (see Figure 6).

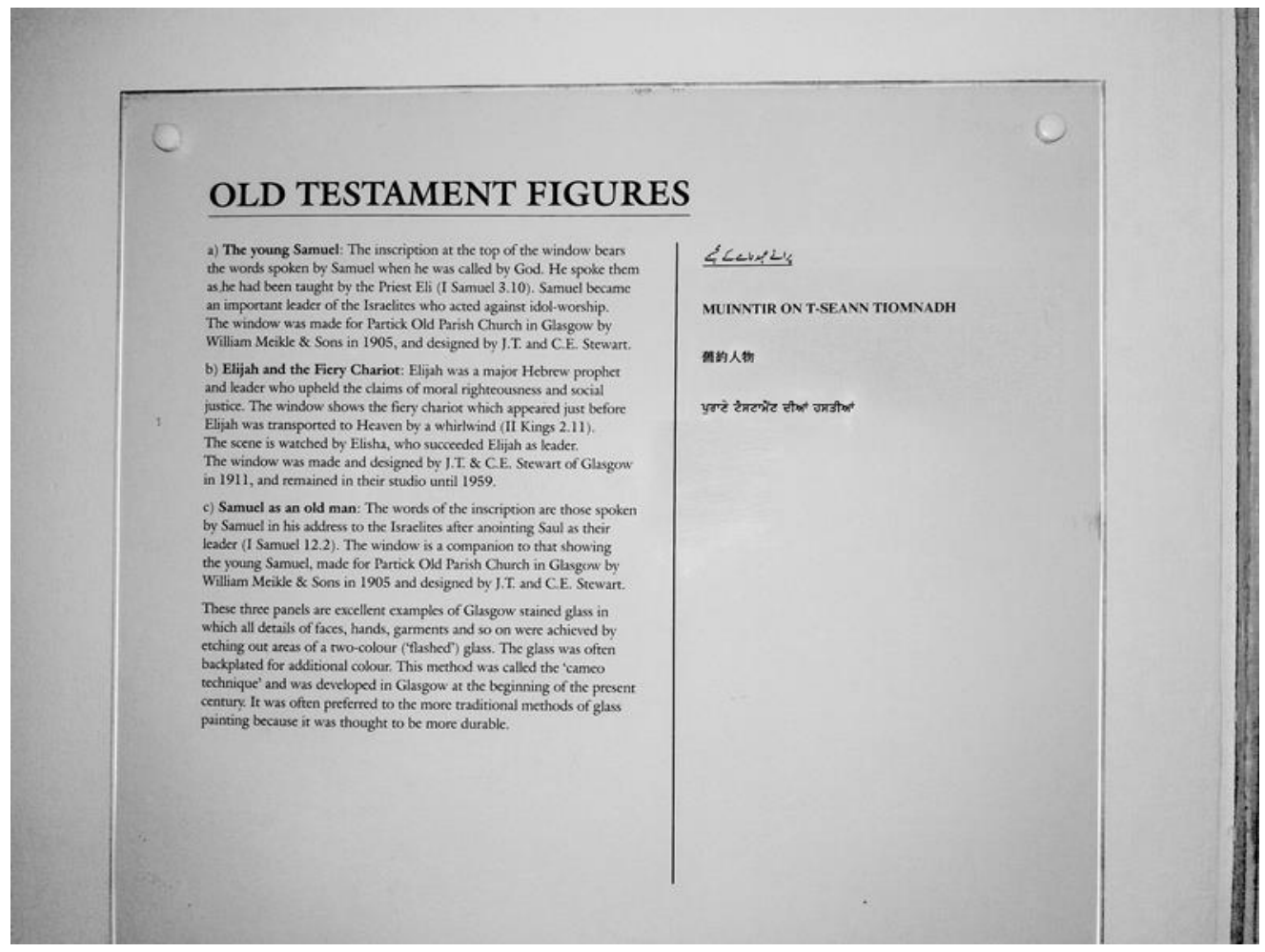

Figure 6. The label of "Old Testament Figures"

The visitors relying on the translated label can infer from the words "Old Testament" that this displayed unit is related to Christianity, but the spatial link to the details in the stained window and to the wider context of Glasgow heritage is lost. They are also not oriented through specific features on the window, that is the space of the object. This is why their engagement with the objects may be lower, and they may move more quickly from one object to another, or probably skip the objects altogether. 
Understandably, providing translations for all labels may not be possible for museums owing to various constraints, for example cost and space. However, deciding what to translate is always motivated. Ravelli (2006) comments that

one exhibition can facilitate particular forms of visitor interaction, can prioritize some meanings in the exhibition rather than others, and can construct a picture of what the subject matter 'is'. (p. 121)

Based on our analysis, the subject-matter in the translated spatial text seems to be displaying "world religions" or the multi-faith Glasgow identity rather than the Glasgow heritage and Christian tradition.

\subsection{Discussion: translated labels in gemosemiotics}

In the analysis above, we have identified instances of a consistent pattern of selective translations possibly having an impact on the spatial text. Overall, a consistent pattern in the four ranks of space to move from Christian tradition to a museum of world religions has been identified, and the way in which museum texts and spaces at different ranks interact with one another has been demonstrated. To explain the role of translation in the framework of geosemiotics, we can perhaps view translated labels as a physical object under the cateogry discussed in Scollon and Scollon (2003) as "visual semiotics". The translated labels as physical objects attract visitors who are unfamiliar with other visual semiotics in the museum space, including the displayed artefacts from distant cultures and labels in an unfamiliar language. The translated labels attract visitors to the associated visual objects, such as an exhibition case or a displayed item. The translated labels also function to point visitors to other features of place semiotics such as the surroundings of the museum or the history of the city, which may otherwise be ignored by visitors.

On the other hand, by not providing translated labels, the curators may fail to draw visitors' attention to the associated visual semiotics or place semiotics that the source texts point to, and therefore the semiotic resources that visitors can refer to for their construction of in-place meaning may be minimized. If the non-provision of translated labels is carefully conceived by the curators to manifest a particular narrative in the museum, then the visitors who rely on the translated labels are likely to be guided to form a different interpretation of the in-place meaning from that of the ST readers, as illustrated in this case study.

\section{Conclusion}

This article applies the theory of geosemiotics to multimodal Translation Studies. We have demonstrated that geosemiotics extends the research focus from visual semiotics to place semiotics, by looking at where visual semiotics (including artefacts, the ST and the TT) are placed in a three-dimensional museum space and at how these semiotics may have an impact on the way in which visitors move around in the museum space and construct the "in-place" meaning of the museum. By bringing in the components of social actors, interaction order, visual semiotics and place semiotics, this theory proves to be useful in exploring the construction of social meanings in concrete and physical space. However, as pointed out above, geosemiotics has been proposed as a general theory, so research that intends to explore a particular type of physical space will need to substantiate the analysis of place semiotics by considering the specific features of that space - for example, by drawing from the studies of museum space in our case study. 
In conclusion, it is hoped that this study has demonstrated how the (non-)provision of translations can have an impact on the construction of in-place meaning in the multimodal museum space.

\section{References}

Carnegie, E. (2009). Catalysts for change?: Museums of religion in a pluralist society. Journal of Management, Spirituality \& Religion, 6(2), 157-169.

Carter, P. (2016). Where are the enslaved?: TripAdvisor and the narrative landscapes of southern plantation museums. Journal of Heritage Tourism, 11(3), 235-249.

Cattrysse, P. (2001). Multimedia and translation: Methodological considerations. In Y. Gambier \& H. Gottlieb (Eds.), (Multi)Media translation (pp. 1-12). Amsterdam: John Benjamins.

Gambier, Y., \& Gottlieb, H. (2001). Multimedia, multilingual: Multiple challenges. In Y. Gambier \& H. Gottlieb (Eds.), (Multi)Media translation (pp. viii-xx). Amsterdam: John Benjamins.

Goffman, E. (1983). The interaction order. American Sociological Review, 48, 1-19.

Hiller, B., \& Tzortzi, K. (2011). Space syntax: The language of museum space. In S. Macdonald (Ed.), A companion to museum studies (pp. 282-301). Oxford: Wiley-Blackwell.

Jiménez Hurtado, C., \& Soler Gallego, S. (2015). Museum accessiblity through translation: A corpus study of pictorial audio dscription. In J. Díaz Cintas \& J. Neves (Eds.), Audiovisual translation: Taking stock (pp. 279-298). Newcastle: Cambridge Scholars.

Kress, G., \& van Leeuwen, T. (1996). Reading images: The grammar of visual design. London: Routledge.

Kress, G., \& van Leeuwen, T. (2001). Multimodal discourse: The modes and media of contemporary communication. London: Bloomsbury.

Liao, M. H. (2018). Museums and creative industries: The contribution of Translation Studies. Journal of Specialised Translation, 29, 45-62.

Lidchi, H. (1991) The poetics and the politics of exhibiting other cultures. In S. Hall (Ed.), Representation: Cultural representations and signifying practices (pp. 151-220). London: Sage.

Macdonald, S. (2005). Accessing audiences: Visiting visitor books. Museum and Society, 3(3), 119-136.

Mateo, M. (2007). Surtitling today: New uses, attitudes and developments. Linguistica Antverpiensia, New Series, 6, 135-154.

Neather, R. (2008). Translating tea: On the semiotics of interlingual practice in the Hong Kong museum of tea ware. Meta, 53(1), 218-240.

Neather, R. (2012). Intertextuality, translation, and the semiotics of museum presentation: The case of bilingual texts in Chinese museums. Semiotica, 192, 197-218.

Neves, J. (2012) Multi-sensory approaches to (audio) describing the visual arts. MonTI, 4, 277-293.

O'Hagan, M., \& Mangiron, C. (2013). Game localization: Translating for the global digital entertainment industry. Amsterdam: John Benjamins.

Oittinen, R. (2001). On translating picture books. Perspectives, 9(2), 109-125.

O'Neill, M. (2006). Museums and identity in Glasgow. International Journal of Heritage Studies, 12(1), 29-48.

Orero, P. (Ed.). (2004). Topics in audiovisual translation. Amsterdam: John Benjamins.

O'Sullivan, C. (2013). Introduction: Multimodality as challenge and resource for translation. The Journal of Specialised Translation, 20, 2-14.

Owens, T. (2012). Tripadvisor rates Einstein: Using the social web to unpack the public meanings of a cultural heritage site. International Journal of Web Based Communities, 8(1), 40-56.

Pang, A. K. M. (2004). Making history in from colony to nation: A multimodal analysis of a museum exhibition in Singapore. In K. O'Halloran (Ed.), Multimodal discourse analysis: Systemicfunctional linguistics (pp. 28-54). London: Continuum.

Ravelli, L. (2006). Museum texts: Communication frameworks. London: Routledge.

Ravelli, L., \& McMurtrie, R. (2015). Multimodality in the built environment: Spatial discourse analysis. London: Routledge.

Scollon, R., \& Scollon, S. W. (2003). Discourses in place: Languages in the material world. London: Routledge. 
Sell, C. (2015). Translation in Japanese Museums: A study of multimodal linguistic landscape. (Unpublished doctoral dissertation). Monash University, Melbourne, Australia.

Zanettin, F. (Ed.). (2008). Comics in translation. Manchester: St. Jerome.

1 In semiotics, linguistics, anthropology and philosophy of language, indexicality is the phenomenon of a sign pointing to some object in the context in which it occurs.

2 This research focuses mainly on intralingual translation, but the argument made here applies to all groups of "less knowledgable" visitors through all forms of mediation in museums, whether linguistic or non-linguistic. For example, Neves (2012, p. 281) asserts that for blind visitors who rely on audio descriptions, words are their museum experience since they do not have alternative access to the exhibitions.

3 "Exhibition texts" refer to those designed to physically form part of the exhibition space, such as wall panels and object labels (Sell, 2015, p. 35). St Mungo Museum also provides translations of leaflets in 12 European languages and Japanese, but as this study focuses on how texts are placed in space, we decide to focus only on exhibition texts.

4 It should be noted that the size and the layout in Figure 2 and Figure 3 are indicated only, not drawn to scale. Some titles of the objects or the thematic cases are not exactly the same as how they are termed in the exhibition, but simply give readers an indication of those religious themes the displayed objects represent. In Figure 2, some decorative objects without textual interpretations in the gallery are not included. 